\title{
Prophylaxis of Surgical Site Infection in Cranial Surgery with Vancomycin Powder Application into Wound
}

\author{
SAMI-UR-REHMAN, ${ }^{1}$ RIFFATULLAH KHAN, ${ }^{2}$ GHAYUR ABBAS ${ }^{1}$ \\ USAMA BIN ZUBAIR, ${ }^{1}$ KAMRAN KHAN, ${ }^{1}$ SAJID NAZEER BHATTI ${ }^{1}$ \\ ${ }^{1}$ Department of Neurosurgery, Shaheed Zulfiqar Ali Bhutto Medical University, PIMS, Islamabad \\ ${ }^{2}$ Abbottabad International Medical College, Abbottabad - Pakistan \\ DOI: https://doi.org/10.36552/pjns.v23i3.351
}

\begin{abstract}
Objective: To see the effect of application of Vancomycin powder directly into the subgaleal space in reducing the postoperative surgical site infections.

Materials and Methods: All the patients who underwent consecutive elective craniotomies from April 2017 to May 2018 Department of Neurosurgery, Shaheed Zulfiqar Ali Bhutto Medical University, PIMS, Islamabad. The control group received the standard routine prophylaxis according to the hospital protocols, whereas the treatment group, in addition to the standard prophylaxis, received Vancomycin powder in the surgical wound in addition to the standard routine prophylaxis. Incidence of infection was the primary outcome evaluated.
\end{abstract}

Results: 182 patients were enrolled in the study, 91 allocated to each the control and treatment group (Vancomycin). Six patients were lost to follow up. There were 90 patients in the control group and 86 patients in the treatment (Vancomycin) group. Both the groups were almost statistically similar. In the control group, $34.09 \%(n=60)$ were male and $17.04 \%(n=30)$ were female. In the treatment group, $29.54 \%(n=52)$ were male and $19.31 \%(n=34)$ were female. The overall rate of surgical site infection (SSI) was 3.97\% (7 out of 176 cases). A statistically significant difference found in infection rate between the treatment group, $0 \%(0$ out of 86 cases) and the control group, 7.77\% (7 out of 90 cases) with the p value of 0.002 . We did not observed any adverse effects from the use of the Vancomycin powder.

Conclusions: The use of topical Vancomycin powder in surgical wounds may significantly reduce the incidence of infection in patients undergoing elective craniotomies. It is a promising means of preventing devastating and harmful postoperative wound infections.

Key Words: Vancomycin; cranial surgery; surgical site infection.

Abbreviations: SSI: Surgical Site Infection.

\section{INTRODUCTION}

Neurosurgery or neurological surgery is the subspecialty in surgery, which deals with the prevention, diagnosis, surgical treatment and rehabilitation of the diseases of the nervous system. The organs involved are the brain, spinal cord, peripheral nerves, and extra-cranial cerebrovascular system. Some of the common surgical procedures performed in neurosurgery include management of congenital malformations, epilepsy surgery, functional neurosurgery, surgical management of vascular conditions of the brain and spinal cord and surgery of the peripheral nervous system.

A craniotomy is an incision through the skull done to excise, repair, or explore the brain, and a craniectomy is a procedure in which a portion of the skull is excised (i.e., removed) surgically to access the brain. ${ }^{1}$ Both craniotomy and craniectomy (CRANI) procedures are used worldwide by the neurosurgeons to treat different disorders of the brain including: brain tumors, traumatic and spontaneous blood clots, bleeding into the brain parenchyma (hemorrhage), 
vascular pathologies such as defects in blood vessels (cerebral aneurysms, or atherosclerosis), abnormal blood vessels (arteriovenous malformations), damage to tissues covering thebrain (dura), localized infections (brain abscesses), diffuse infections (epidural abscesses, subdural empyema) severe nerve or facial pain (trigeminal neuralgia or tic douloureux), trauma to the skull (skull fractures) and some seizure disorders (epilepsy). ${ }^{2}$

The number of CRANI done per year is gradually increasing all over the world. Alone in US more than 100,000 procedures are performed each year. ${ }^{3}$ Surgical Site Infection (SSI) is major problem for all of the surgeons around the world and has catastrophic consequences resulting in increased morbidity, prolonged in hospital stay, reduced life quality, increased costs, unplanned readmissions and mortality. ${ }^{4}$ A recent prevalence study states that SSI accounts for $31 \%$ of all healthcare associated infections. ${ }^{5}$ The rate of developing SSI after a neurosurgical procedure should ideally be low because in proximity to them there are no potentially contaminated fields like gastrointestinal or urogenital tract. But, they are in close proximity with the cerebrospinal fluid (CSF) and central nervous system, both of which are sterile. ${ }^{6}$ The rate of postoperative complicated CRANI cases with SSI is $2.2-4.7 \%$. $^{7}$ However, in low and middle-income setups slightly higher rates are reported. In Malaysia, a study reported the SSI rate after CRANI procedures to be $7.7 \%{ }^{8}$ The economic magnitude of burden is reported as much as $£ 9283$ for each SSI after CRANI. ${ }^{9}$ The main objective of our study was to assess the overall rate of SSI after CRANI at Department of Neurosurgery, Shaheed Zulfiqar Ali Bhutto Medical University and to evaluate the role of local Vancomycin powder application into the CRANI wound in effective prophylaxis of SSI after CRANI.

\section{PATIENTS AND METHODS}

\section{Study Design and Sampling}

This Randomized controlled trial (RCT) was carried out from April 2017 to May 2018 at the department of Neurosurgery, Shaheed Zulfiqar Ali Bhutto Medical University, PIMS, Islamabad. The sample was gathered by using non-probability consecutive sampling method with 91 patients in each group. The sample size was calculated by keeping Level of significance $=5 \%$, Power of test $=95 \%$, Surgery with
Vancomycin powder $=(\mathrm{P} 1) 0 \%,{ }^{6}$ Surgery without Vancomycin powder $=(\mathrm{P} 2) 13 \% .^{6}$

\section{Inclusion Criteria}

Patients of both genders undergoing craniotomy/ craniectomy were included in our study.

\section{Exclusion Criteria}

Children under age of 3 years, Patients with prior history of infection at the surgical site, patients undergoing biopsy or patients with burr hole placement only, allergic to Vancomycin. Patients who develop a CSF leak and those with serious medical illnesses were excluded from the study.

\section{Data Collection}

The study started after taking approval from the hospital ethics committee. All patients who were admitted to Neurosurgery ward and underwent CRANIL procedures were enrolled in the study. Informed written consent was taken from each patient. Initial data about age, contact number and date of admission was recorded on predesigned Proforma. All patients received an intravenous dose of $1 \mathrm{~g}$ of Ceftriaxone 30 minutes before incision. All the patients were scrubbed with pyodine scrub and spirit. In one group of patient's Vancomycin powder was applied to the bone flap, and subgaleal space before closing the wound. In the control group no Vancomycin powder was applied. The patients were randomized to group A (with intrawound Vancomycin application) and group B (without Vancomycin application) by lottery method. The procedure was performed under general anesthesia in all patients by consultant Neurosurgeon. Post operatively patients were kept in Head Injury Unit or Surgical Ward 3 accordingly. The wound was examined on $3^{\text {rd }}, 5^{\text {th }}$ and $7^{\text {th }}$ postoperative days for any signs of SSI. On full recovery patients were discharged from hospital. The patients were followed after 30 days and wound was thoroughly examined again for any signs of SSI.

\section{Data Analysis}

The data was entered in SPSS version 20. Descriptive statistics were used to calculate means \pm standard deviation for quantitative variables i.e. age. Frequencies with percentage were calculated for qualitative variables, i.e. gender, occurrence of CSF leak and treatment efficacy. The Chi-square test was 
used to compare surgical site infection at post-operative days 3,5 , 7 , at the time of discharge and at $30^{\text {th }}$ day. The efficacy was compared by applying chi-square test between both groups. Effect modifiers like age and gender were controlled by stratification. Post stratification chisquare test was applied.

\section{RESULTS}

We enrolled 182 patients in our study who underwent consecutive elective craniotomy procedures from April 2017 to May 2018 at the department of Neurosurgery, Shaheed Zulfiqar Ali Bhutto Medical University, Pakistan Institute of Medical Sciences (PIMS) Islamabad. In all, six patients, who lost to follow-up.

\section{Gender Distribution}

Males were predominant. $63.63 \%$ $(\mathrm{n}=112)$ were male and $36.36 \%$ $(n=64)$ were female. In the control group, $34.09 \%(\mathrm{n}=60)$ were male and $17.04 \%(\mathrm{n}=30)$ were female. In the treatment group, $29.54 \%(\mathrm{n}=$ 52) were male and $19.31 \%(\mathrm{n}=34)$ were female.

\section{Age Incidence}

Among the 176 patients, the youngest was 15 years old and the oldest patient was 75 years old with a mean age of 47.95 years and a standard deviation of 12.03. The highest number of patients was between ages 50 and 60 i.e., 63 with the lowest number of patients above age 70 .

\section{Infection}

Out of the 176 patients included in our study, seven $(3.97 \%)$ surgical site infections were encountered. In the 86 patients included in the
Table 1: SSI in both the groups (Application of chi-square).

\begin{tabular}{|l|c|c|c|c|}
\hline \multirow{2}{*}{ SSI Status } & \multicolumn{2}{|c|}{ Study Group } & \multirow{2}{*}{$\begin{array}{c}\text { P value } \\
\text { Chi-square }\end{array}$} \\
\cline { 2 - 3 } & Control & Vancomycin & & \\
\cline { 2 - 4 } Present & $7(3.97 \%)$ & $0(0 \%)$ & $7(3.97 \%)$ & \multirow{2}{*}{0.002} \\
\hline Absent & $83(47.15 \%)$ & $86(48.86 \%)$ & $169(96.02 \%)$ & \\
\hline Total & $90(51.14 \%)$ & $86(48.86 \%)$ & $176(100 \%)$ & \\
\hline
\end{tabular}

Table 2: Surgical site infection distribution by gender.

\begin{tabular}{|l|l|l|c|c|c|}
\hline \multicolumn{2}{|c|}{} & \multicolumn{2}{c|}{ SSI Status } & \multirow{2}{*}{ Total } & $\begin{array}{c}\text { P value } \\
\text { Chi- } \\
\text { Square }\end{array}$ \\
\cline { 3 - 5 } & Present & Absent & & \multirow{2}{*}{0.656} \\
\hline \multirow{2}{*}{ Gender } & Male & $5(4.46 \%)$ & $107(95.53 \%)$ & $112(100 \%)$ & \\
\cline { 2 - 5 } & Female & $2(3.12 \%)$ & $62(96.87 \%)$ & $64(100 \%)$ & \\
\hline \multicolumn{2}{|l|}{ Total } & $7(3.97 \%)$ & $169(96.02 \%)$ & $176(100 \%)$ & \\
\hline
\end{tabular}

Table 3: Surgical Site Infection at day 3.

\begin{tabular}{|l|c|c|c|c|}
\hline \multirow{2}{*}{$\begin{array}{l}\text { SSI } \\
\text { Status }\end{array}$} & \multicolumn{2}{|c|}{ Study Group } & \multirow{2}{*}{ Total } & $\begin{array}{c}\text { P value } \\
\text { Chi-square }\end{array}$ \\
\cline { 2 - 3 } \cline { 2 - 3 } & Control & Vancomycin & & \\
\cline { 1 - 3 } Present & $2(1.13 \%)$ & $0(0 \%)$ & $2(1.13 \%)$ & \multirow{2}{*}{0.016} \\
\hline Absent & $88(50 \%)$ & $86(48.86 \%)$ & $174(98.86 \%)$ & \\
\hline Total & $90(51.13 \%)$ & $86(48.86 \%)$ & $176(100 \%)$ & \\
\hline
\end{tabular}

Table 4: Surgical Site Infection at day 5.

\begin{tabular}{|l|c|c|c|c|}
\hline \multirow{2}{*}{$\begin{array}{l}\text { SSI } \\
\text { Status }\end{array}$} & \multicolumn{2}{|c|}{ Study Group } & \multirow{2}{*}{ Total } & $\begin{array}{c}\text { P value } \\
\text { Chi-square }\end{array}$ \\
\cline { 2 - 3 } \cline { 2 - 3 } & Control & Vancomycin & & \\
\cline { 2 - 3 } Present & $4(2.27 \%)$ & $0(0 \%)$ & $4(2.27 \%)$ & \multirow{2}{*}{0.038} \\
\hline Absent & $86(48.86 \%)$ & $86(48.86 \%)$ & $172(97.72 \%)$ & \\
\hline Total & $90(51.13 \%)$ & $86(48.86 \%)$ & $176(100 \%)$ & \\
\hline
\end{tabular}

Table 5: Surgical Site Infection at day 7.

\begin{tabular}{|l|c|c|c|c|}
\hline \multirow{2}{*}{$\begin{array}{l}\text { SSI } \\
\text { Status }\end{array}$} & \multicolumn{2}{|c|}{ Study Group } & \multirow{2}{*}{ Total } & \multirow{2}{*}{$\begin{array}{c}\text { P value } \\
\text { Chi-square }\end{array}$} \\
\cline { 2 - 4 } \cline { 3 - 4 } & Control & Vancomycin & \\
\hline Present & $1(0.56 \%)$ & $0(0 \%)$ & $1(0.56 \%)$ & \multirow{2}{*}{0.234} \\
\hline Absent & $89(50.56 \%)$ & $86(48.86 \%)$ & $175(99.06 \%)$ & \\
\hline Total & $90(51.13 \%)$ & $86(48.86 \%)$ & $176(100 \%)$ & \\
\hline
\end{tabular}


treatment group there was no SSI identified. Ninety patients were allotted to the control group and seven $(7.77 \%)$ SSIs were identified. Out of the 112 males included in this study, 4.46\% ( $\mathrm{n}=5)$ developed SSI. On the other hand, in the 64 females only $3.12 \%(\mathrm{n}=2)$ SSIs were identified. The patients in the $7^{\text {th }}$ decade of their life suffered from SSIs more as compared to the other age groups. In this age group, the SSI rate was $16 \%$ (4 out of 25 ) followed by $3.17 \%$ (2 out of 61) infected cases in the age group of $6^{\text {th }}$ decade of life. Our results showed that overall $7.77 \%$ (7 out of 90 patients) in the control group suffered from SSIs as compared to the treatment group with no SSIs in 86 patients. This is statistically significant as the $p$ value turned out to be 0.002 . On day 3 two SSIs were diagnosed in two patients (one a 58 year old male and other a 60 year old female). On day five, we diagnosed four patients with SSI and one SSI was diagnosed on day 7. In the treatment group, no patients demonstrated post-operative SSI ( $p>0.05$ ). In those patients diagnosed with SSIs, swabs from wounds were sent for culture and sensitivity and were started empiric antimicrobial therapy with Vancomycin/ Amikacin combination soon after. The causative pathogens were Staphylococcus aureus in four patients and Staphylococcus Epidermidis in three.

\section{DISCUSSION}

SSI after neurosurgical procedures is a huge problem for neurosurgeons as they are a major source of morbidity and mortality. In general, neurosurgeons have reported postoperative SSI rates to be lower than those reported by other surgical specialists have. However, with the advancement in the technology, surgical microscopes and endoscopes have been introduced which has led to a prolonged neurosurgical procedure. Along with that increasing use of implants and other foreign material such as shunts, spinal implants, cranioplasty plates/mesh, and artificial dural substitutes have increased the risk of postoperative SSIs. Overall rate of SSIs in neurosurgical departments has been reported to be from $0 \%$ to $15 \%$. SSI rate after CRANI procedures is about $6 \% .^{8}$ Throughout the years, many measures have been developed and implemented to decrease the SSIs; they include preoperative preparation of the patient, clipping the hair, proper surgeon's preparation, prophylactic antibiotics and the latest option added to it is sprinkling Vancomycin powder into the surgical wound. Although it has been studied extensively in spine surgeries and have, shown benefit as reported by some authors to decrease the SSIs from $15 \%$ to $0 \%{ }^{9}$ still in cranial surgery it is being evaluated and there is less literature published.

Our study, which was a randomized control trial and enrolled 182 consecutive patients undergoing elective clean cranial neurosurgery conducted at Department of Neurosurgery, Shaheed Zulfiqar Ali Bhutto Medical University from April 2017 until May 2018. The study was conducted with a view to establish the efficacy of topical Vancomycin powder into the surgical wound in decreasing the SSIs, following non-traumatic, clean neurosurgical procedures. It will be helpful in reducing the rate of SSIs in our setups and other developing countries.

Our study included 182 patients, 91 in each group, but six patients were lost to follow up. Ages of 176 patients ranged from $15-75$ years. Most of the patients $(156,88.63 \%)$ were in between 30-69 years with mean age of 47.95 years. The mean age of the 90 patients enrolled in the control group was 49.47 years with standard deviation of 11.89 . The mean age of the 86 patients in the treatment group was 46.36 years with standard deviation of 12.03. In a similar study performed at the Department of Neurosurgery, Hospital of the University of Pennsylvania and published in The Journal of Neurosurgery, the number of patients was 150 with a mean age of $52.1 \pm 16.6$ years in the control group and $49.4 \pm 15.6$ in the treatment group. ${ }^{10}$

Another large prospective cohort study included three hundred and fifty five patients. Two hundred and five patients received Vancomycin in the subgaleal space after CRANI procedures. The mean ages of the patients in both the groups were reported to be higher 
with $54.5 \pm 2.5$ years in the control group and $52.4 \pm$ 2.2 in the treatment group. ${ }^{11}$

In this study, we observed that of the 176 patients, seven developed surgical site infections, thus the overall rate of SSI in our study turned out to be $3.97 \%$. All of the SSIs were deep incisional infections that required surgical intervention. Our findings are consistent with the SSI rate reported by Abdullah et al. They had six infected cases out of 150 patients and the overall SSI incidence was $4 \% .^{12}$ Similarly, another large study including 2865 patients undergoing craniotomy procedures reported overall SSI rate of $3.6 \%$ (104 out of 2865). ${ }^{3}$ Our findings are almost consistent with both these studies. However, our SSI rate is higher than the $2.2 \%$ that was reported by Ravikumar et al in a similar study. ${ }^{13}$ It is also higher than the SSI rate of $2.2 \%$ reported by multiple hospitals to the National Healthcare Safety Network. ${ }^{11}$

Of the 75 patients in the control group, Abdullah et al reported five SSIs and in the treatment group, they had only one infected case out of 75 patients. ${ }^{14}$ Our findings are consistent with their findings as we had seven SSIs out of the 90 patients in the control group and no SSI in the 86 patients in the treatment group.

Mallela et al. in their study included 150 patients in the control group and 205 patients in the treatment group. They had $9(6 \%)$ in the control group and only $1(0.49 \%)$ in the treatment group. ${ }^{16}$ Our findings are consistent with the findings of this study. In our study, we had seven $(7.77 \%)$ SSIs out of 90 patients in the control group; however, we had no infected case in in the treatment group.

Regarding the sex distribution in our study, out of the 176 patients $112(63.6 \%)$ were male and 64 $(36.4 \%)$ were female. Male to female ratio was 1.75:1. The rate of SSIs among males was $4.46 \%$ (5 out of 112 ) and in females was $3.12 \%$ (2 among 64). The rate of SSIs was slightly higher in males, but statistically not significant ( $\mathrm{p}$ value 0.65 ). These findings are consistent with the findings of Abdullah et al, Mallela et al. and Ravikumar et al., where they could not find any statistically significant association between gender and SSIs. ${ }^{11,12,14}$

The rate of surgical site infections (SSIs) in different age groups was $3.17 \%$ (2 out of 63) in the age group 50-59 years, $16 \%$ (4 out of 25) in $60-69$ years and $100 \%$ ( 1 out of 1$)$ in the $70-79$ years. It was highest $16 \%$ in the age groups $60-6 \%$ (4 out of 25 patients). Out of the seven infected cases $2(1.13 \%)$ were identified on $3^{\text {rd }}$ post-operative day, 4 cases on the $5^{\text {th }}$ post-operative day and 1 on the $7^{\text {th }}$ postoperative day $(p>0.05)$. Similar results have been reported in other studies as well. ${ }^{15-20}$

\section{CONCLUSION}

Our study demonstrates that the use of topical Vancomycin powder into the craniotomy wound is associated with decreased rate of surgical site infection (SSIs). The findings suggest that the topical Vancomycin powder is effective, safe and leads to decrease costs. These results are comparable to international studies quoted earlier and have been practiced by various other specialties as well.

\section{Additional Information}

Disclosures: Authors report no conflict of interest.

Human Subjects: Consent was obtained by all patients/ participants in this study.

Conflicts of Interest:

In compliance with the ICMJE uniform disclosure form, all authors declare the following:

Financial Relationships: All authors have declared that they have no financial relationships at present or within the previous three years with any organizations that might have an interest in the submitted work.

Other Relationships: All authors have declared that there are no other relationships or activities that could appear to have influenced the submitted work.

Address for Correspondence: Dr. Sami-ur-Rehman

Resident Neurosurgeon, PIMS, Islamabad-Pakistan Email: samirahman588@gmail.com

\section{REFERENCES}

1. Stedman's Medical Terminology. Creason C, editor. Philadelphia: Lippincott Williams \& Wilkins; 2011.

2. Yin $\mathrm{CH}$. Risk factors and outcomes associated with surgical site infections afer craniotomy and craniectomy." University of Iowa; 2012.

3. Chiang HY, Kamath AS, Pottinger JM, Greenlee JD, Howard MA, 3rd, Cavanaugh JE, et al. Risk factors and outcomes associated with surgical site infections after craniotomy or craniectomy. J Neurosurg. 2014; 120 (2): 509-21.

4. Cassir N, De La Rosa S, Melot A, Touta A, Troude L, Loundou A, et al. Risk factors for surgical site infections after neurosurgery: A focus on the postoperative period. Am J Infect. 2015; 43 (12): 12881291.

5. Magill SS, Hellinger W, Cohen J, Kay R, Bailey C, 
Boland B, et al. Prevalence of healthcare-associated infections in acute care hospitals in Jacksonville, Florida. Infect Control Hosp Epidemiol. 2012; 33 (3): 283-91.

6. Walcott BP, Redjal N, Coumans J-VCE. Infection following operations on the central nervous system: deconstructing the myth of the sterile field. Neurosurg Focus, 2012; 33 (5): E8.

7. Fang C, Zhu T, Zhang P, Xia L, Sun C. Risk factors of neurosurgical site infection after craniotomy: A systematic review and meta-analysis. Am J Infect Control, 2017.

8. Buang SS, Haspani MS. Risk factors for neurosurgical site infections after a neurosurgical procedure: a prospective observational study at Hospital Kuala Lumpur. Med J Malaysia, 2012; 67 (4): 393-8.

9. Davies BM, Jones A, Patel HC. Implementation of a care bundle and evaluation of risk factors for surgical site infection in cranial neurosurgery. Clin Neurol Neurosurg. 2016; 144: 121-5.

10. Caroom C, Tullar JM, Benton Jr EG, Jones JR, Chaput $\mathrm{CD}$. Intrawound vancomycin powder reduces surgical site infections in posterior cervical fusion. Spine (Phila Pa, 1976), 2013; 38 (14): 1183-7.

11. Abdullah KG, Attiah MA, Olsen AS, Richardson A, Lucas TH. Reducing surgical site infections following craniotomy: examination of the use of topical vancomycin. J Neurosurg. 2015; 123 (6): 1600-4.

12. Ravikumar V, Ho AL, Pendhakar AV, Sussman ES, Kwong-Hon Chow K, Li G. The Use of Vancomycin Powder for Surgical Prophylaxis Following
Craniotomy. Neurosurgery, 2017; 80 (5): 754-8.

13. Edwards JR, Peterson KD, Mu Y, Banerjee S, AllenBridson K, Morrell G, et al. National Healthcare Safety Network (NHSN) report: data summary for 2006 through 2008, issued December 2009. Am J Infect Control, 2009; 37 (10): 783-805.

14. Mallela AN, Abdullah KG, Brandon C, Richardson AG, Lucas TH. Topical Vancomycin Reduces SurgicalSite Infections After Craniotomy: A Prospective, Controlled Study. Neurosurgery, 2017.

15. Hervin R. Dashti, Humain Baharvahdat, Robert F. Spetzler, Eric Sauvageau, Steven W. Chang, Michael F. Stiefel, et al. Operative intracranial infection following craniotomy. Neurosurg Focus, 2008; 24 (6): E10.

16. O'Keeffe AB, Lawrence $\mathrm{T}$, Bojanic S. Oxford craniotomy infections database: a cost analysis of craniotomy infection. Br J Neurosurg. 2012; 26 (2): 265-9.

17. Kourbeti IS, Jacobs AV, Koslow M, Karabetsos D, Holzman RS. Risk factors associated with postcraniotomy meningitis. Neurosurgery, 2007; 60 (2): 317-26.

18. Proctor LM. The human microbiome project in 2011 and beyond. Cell host \& microbe. 2011; 10 (4): 287-91.

19. Shiono Y, Watanabe K, Hosogane N, Tsuji T, Ishii K, Nakamura M, et al. Sterility of posterior elements of the spine in posterior correction surgery. Spine (Phila $\mathrm{Pa}$, 1976), 2012; 37 (6): 523-6.

20. Miller MB, Bassler BL. Quorum sensing in bacteria. Annual Reviews in Microbiology, 2001; 55 (1): 165-99.

\begin{tabular}{|c|c|c|c|}
\hline \multicolumn{4}{|c|}{ AUTHORSHIP AND CONTRIBUTION DECLARATION } \\
\hline Sr.\# & Author's Full Name & Intellectual/Contribution to Paper in Terms of: & \\
\hline 1. & $\begin{array}{l}\text { Sami urRehman } \\
\text { (Main/Principal Author). }\end{array}$ & 1. Proposed topics and Basic Study Design & $\begin{array}{l}\text { Signature by the } \\
\text { author(s) }\end{array}$ \\
\hline 2. & $\begin{array}{l}\text { Riffatullah Khan } \\
\text { (2nd Author) }\end{array}$ & 2. Data collection and calculations & Sanis Kulve. \\
\hline 3. & $\begin{array}{l}\text { Ghayur Abbas } \\
\text { (3rd Author) }\end{array}$ & $\begin{array}{l}\text { 3. Analysis of data and interpretation of results } \\
\text { etc. }\end{array}$ & $\frac{\text { Feflat }}{\text { Gecerfon }}$ \\
\hline 4. & $\begin{array}{l}\text { Usama Bin Zafar } \\
\text { (4th Author) }\end{array}$ & 4. Literature review and manuscript writing & 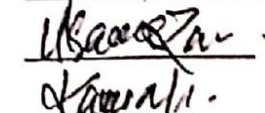 \\
\hline 5. & $\begin{array}{l}\text { Kamran Khan } \\
\text { (5th Author) }\end{array}$ & $\begin{array}{l}\text { 5. Paper writing, referencing, Data } \\
\text { Calculations and quality insurer }\end{array}$ & seyre \\
\hline 6. & $\begin{array}{l}\text { Sajid Nazeer Bhatti } \\
\text { (6th Author) }\end{array}$ & 6. Study Design and methodology & \\
\hline
\end{tabular}

Date of Submission: 06-07-2019

Date of Revision: 30-07-2019
Date of Online Publishing: 25-09-2019

Date of Print: 30-09-2019 